\title{
The Effects of Neonatal Stunting on the Development of Rats: Effects of Early Single Dose Cortisone on Dental Development and Maturation of Nursling and Mature Rats
}

\author{
HAROLD DINER, MAY D. CHOU, AND EDNA H. SOBEL ${ }^{(20)}$ \\ Departments of Dentistry and Pediatrics and Rose F. Kennedy Center for Research in Mental Retardation and Human \\ Development, Albert Einstein College of Medicine, Bronx, New York, USA
}

\section{Summary}

Lags in eruption schedules were evident at age 21 days in all molar teeth of rats given a single dose of cortisone acetate at age 4 days. The abnormalities were most pronounced in the second and third molars. Although there were no anatomic coronal variations of first and second molars, delays in root development and crown and root mineralization were quite apparent in treated animals. The most striking changes occurred in the third molars. Differences between control and treated animals in mandibular third molar dimension were significant $(P<0.001)$. Alterations in third molar crown morphology were also noted in treated animals. These included reductions in size or total absence of the mesiobuccal cusps and the buccal grooves. Cusp height, in general, appeared more diminutive and less ordered anatomically. Calcification and eruption were also considerably delayed. It is apparent that the histo- and morphodifferentiation periods in the development of this tooth were affected.

At 84 days, there were no significant dimensional coronal differences of first and second molars. The reduction in third molar crown size persisted $(P<0.001)$, as did the anatomic variations noted in 21-day treated animals. Differences of crown and root calcification between control and treated groups were not discernible. Comparisons of molar root lengths showed no significant differences.

\section{Speculation}

Developmental dental abnormalities may reflect interferences with normal somatic growth. They thus may provide a diagnostic chronology for the onset and persistence of systemic insult.

The purpose of this study was to investigate the effects of a single dose of cortisone acetate given during a critical period in dental development on the size and morphology of the molar teeth of the laboratory rat examined 21 days after birth (group I), and to evaluate any permanently imposed alterations 84 days after birth (group II).

\section{MATERIALS AND METHODS}

The specimens examined in this study were those utilized by Sobel in her work on the early and late effects of administration of cortisone in the neonatal period on physical growth ${ }^{(16)}$. All of the rats were offspring of cesarian-derived Sprague-Dawley descendents from the Charles River Laboratories. Those utilized for the dental study were selected from among the animals used for the growth and behavioral studies.

For treated animals, cortisone acetate, $1.25 \mathrm{mg}$ in $0.05 \mathrm{ml}$ solution (Upjohn, sterile aqueous suspension) was given im in the left lateral thigh on day 4 . For controls, $0.05 \mathrm{ml}$ isotonic saline was given in the same site and on the same day. Animals were killed at 21 or 84 days of age by ip injection of pentobarbital.

The bodies of 2l-day-old animals were processed before soft tissues were removed. At age 84 days, the skulls and mandibles were cleaned of soft tissues by placement with a colony of Domesties escarabochos. Skeletons were cleared with $\mathrm{KOH}$ and increasing concentrations of glycerin, stained with Alizarin red-S, and stored in glycerin (method of Dawson (9)). The mandibles were disarticulated for direct visual review of both upper and lower jaws, and to facilitate direct caliper and micrometric measurements of tooth dimensions.

\section{GROUP I (2I-DAY SPECIMENS)}

In controls $(n=24)$, the mandibular third molars, although unerupted, were clearly visible, whereas the third molars of treated animals $(n=14)$ were only faintly discernible (Fig. 1). Because in situ measurements of erupting teeth can be misleading, these tooth buds were enucleated. This was accomplished easily since root formation had not yet been initiated. Their mesiodistal diameters were measured across the occlusal table, which provided the most stable and replicable coronal dimensions. The diminutive size of these teeth made direct caliper measurement difficult and instead an occular micrometer mounted in a dissecting microscope was used (Fig. 2).

\section{GROUP II (84-DAY SPECIMENS)}

The combined coronal widths of the maxillary first and second molars were compared in control and treated animals. Direct caliper measurement in situ at the cervical necks of these teeth was utilized. This was done to eliminate any errors in measurement possibly imposed by occlusal and interproximal attrition and wear, and because close molar contact abutment made replicative measurements at the heights of contour potentially unreliable.

Since removal of teeth in dried specimens predisposed to coronal and radicular fracture, mesiodistal caliper measurements of mandibular third molars crowns in 84-day control and treated animals were performed in situ at the cervical necks (Fig. 4). Measurements across the occlusal table, as in 21-day specimens, were no longer considered reliable because of masticatory wear.

To determine further whether catch-up growth in dental maturation was demonstrable, the molar root lengths of control and treated animals were recorded. The distal roots of the maxillary third molars and the mesial roots of the maxillary first molars were measured from cervical necks to root apices. Ease of dissection and exposure were the determinants in selecting these anatomic sites. All measurements of the third molar crown widths 


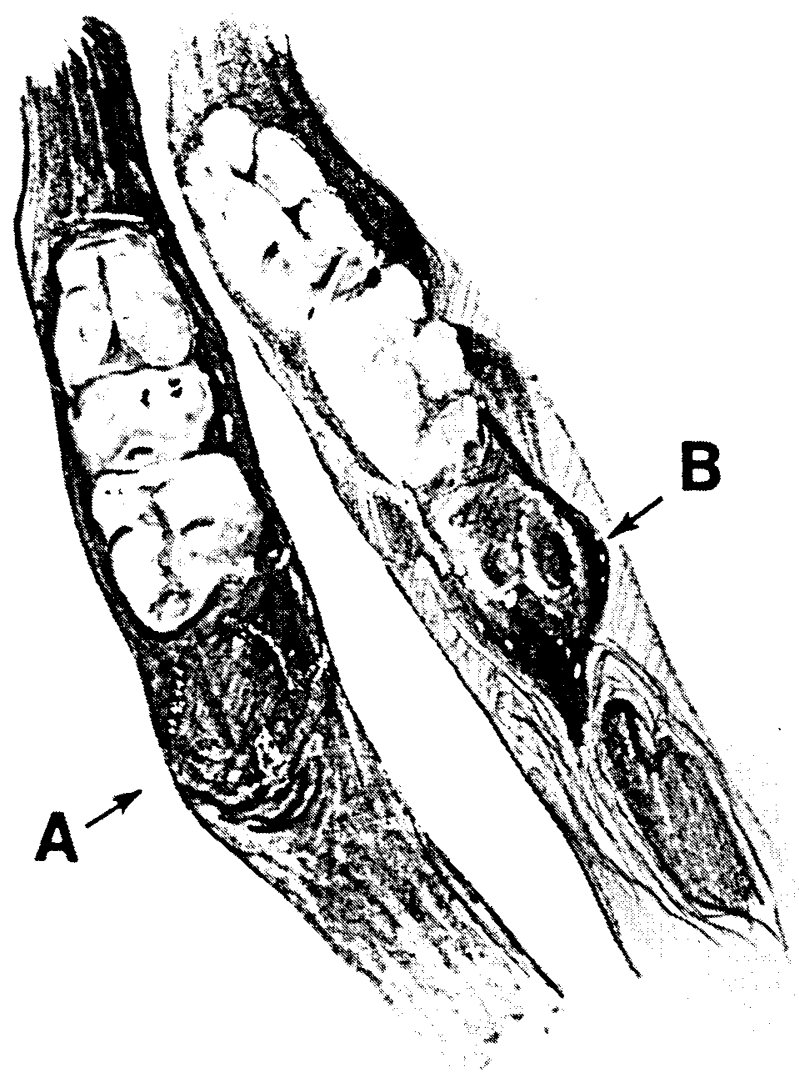

Fig. 1. Disarticulated mandibles of treated $(A)$ and control $(B)$ animals at 21 days of age. Eruptive differences are most marked in the third molar areas (arrow).
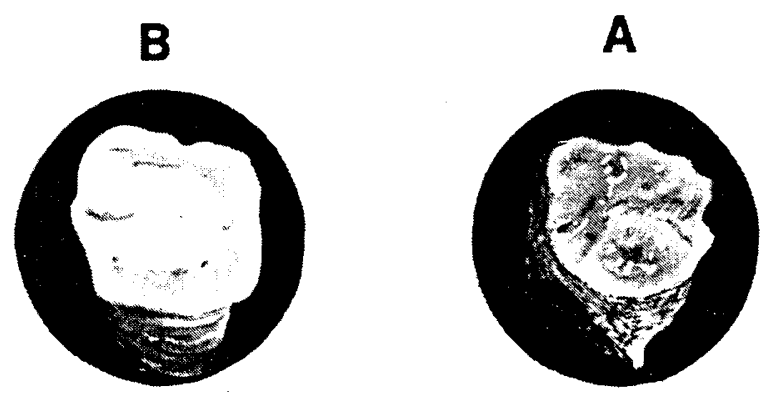

Fig. 2. Enucleated third molars in treated $(A)$ and control $(B)$ animals at 21 days. Tooth size, morphology, and degree of calcification are considerably altered in the treated animal.

were made on the left mandible; the right maxilla was used for the other measurements.

\section{RESULTS}

\section{FINDINGS AT 21 DAYS}

Lags in eruption schedules were evident in all molar teeth of treated animals, but were most pronounced in the second and third molars (Fig. 1). This delay created the illusion of reduced coronal dimension of the first and second molars.
The most striking changes occurred in the third molars. Differences in left mandibular third molar dimensions between control and treated animals were very significant (treated $(n=14), 1.14$ $\pm 0.07 \mathrm{~mm}$; control $(n=24), 1.33 \pm 0.22)(P<0.001))$. Alterations in third molar crown morphology were also noted in treated animals. These included reductions in size or total absence of the mesiobuccal cusps and the buccal grooves (Fig. 2). Calcification and eruption were also considerably delayed. Although there were no anatomic coronal variations of first and second molars, delays in root development and in crown and root mineralization were quite apparent in all three molar teeth from cortisone-treated animals (Figs. 1, 2, and 3).

\section{FINDINGS AT 84 DAYS}

At 84 days, there were no significant dimensional coronal differences of first and second molars of the right maxilla between control and treated animals (Table 1). However, the reduction in left mandibular third molar crown size persisted $(P<0.001$; Table 2 , as did the anatomic variations noted in 21-day treated animals (Fig. 4).

Differencs of crown and root calcification between control and treated groups were not discernible. Distal root lengths of right maxillary third molars did not differ, nor were the mesial roots of the right maxillary first molars significantly different from those of the controls (Table 2).

\section{DISCUSSION}

The influences mediating tooth germ formation are the genetic potential of the tooth germ itself, the immediate local environment 

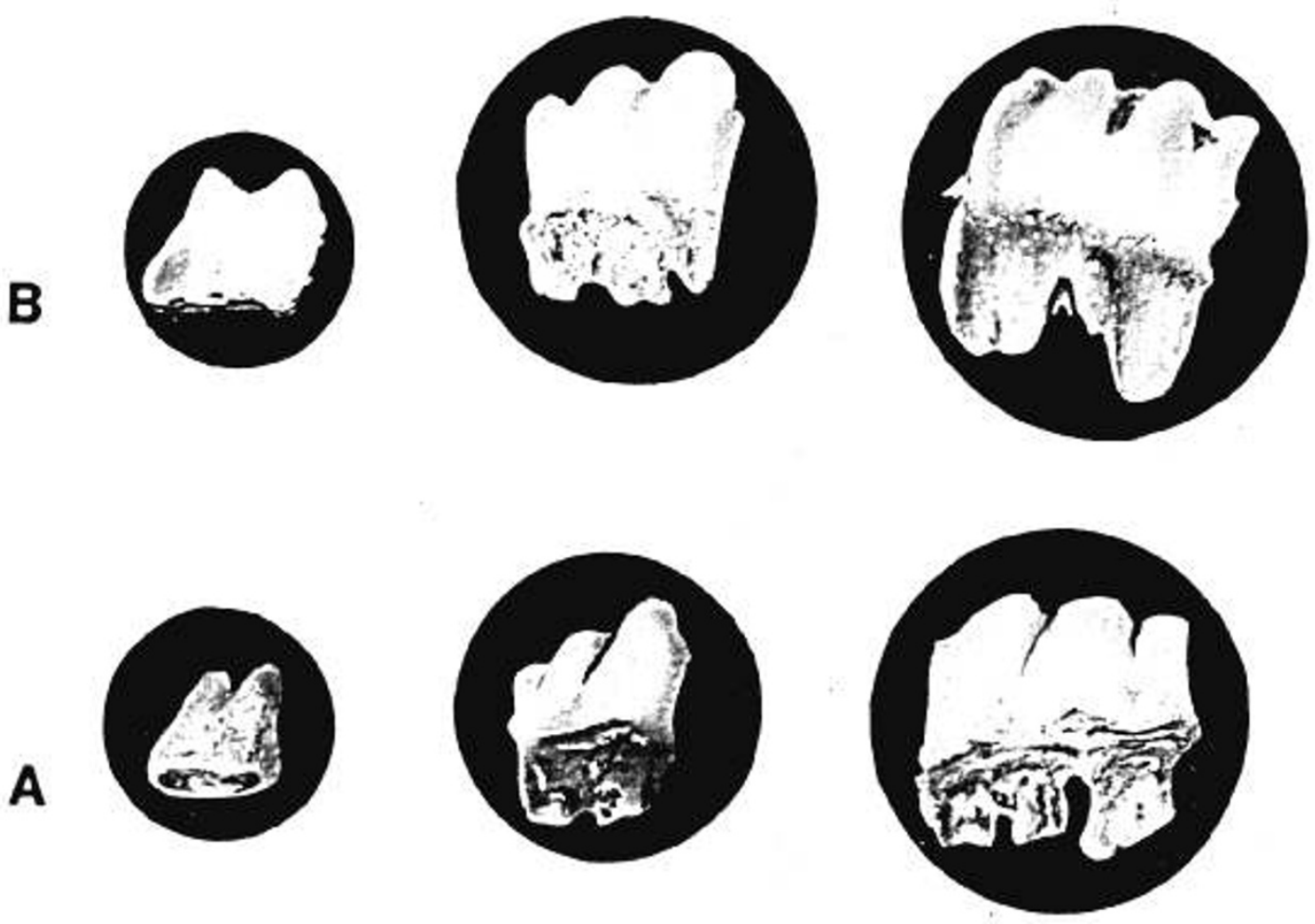

Fig. 3. Enucleated first, second, and third molars from treated $(A)$ and control $(B)$ 21-day-old animals.

Table 1. Results in 84-day-old animals (mean $\pm 1 S D$ )

\begin{tabular}{lccc}
\hline & $\begin{array}{r}\text { Treated } \\
(n=15)\end{array}$ & $\begin{array}{c}\text { Control } \\
(n=7)\end{array}$ & $P$ \\
\hline $\begin{array}{l}\text { Ist and 2nd molars (mm) (right } \\
\text { maxilla) }\end{array}$ & $5.01(0.08)$ & $5.04(0.05)$ & NS \\
$\begin{array}{l}\text { 3rd molars (mm) (left mandi- } \\
\text { ble) }\end{array}$ & $1.64(0.16)$ & $1.93(0.08)$ & $<0.001$ \\
\hline
\end{tabular}

Table 2. Results in 84-day-old animals (mean $\pm 1 S D)$ : Right maxilla

\begin{tabular}{llll}
\hline & $\begin{array}{c}\text { Treated } \\
(n=12)\end{array}$ & $\begin{array}{l}\text { Control } \\
(n=9)\end{array}$ & $P$ \\
\hline 1st molar mesial root $(\mathrm{mm})$ & $2.98(0.19)$ & $3.02(0.11)$ & NS \\
3rd molar distal root $(\mathrm{mm})$ & $2.06(0.19)$ & $2.04(0.07)$ & NS \\
\hline
\end{tabular}

around the developing tooth germ, and the general environment of the individual as a whole (17). Developmentally, teeth are generally morphogenetically static; they can be altered morphologically and in composition only during their formative periods and are essentially unaffected once dental maturation is complete.

Endocrine disturbances affect the size or form of teeth only if such effects occur during morphodifferentiation (late bell stage) which precedes calcification $(12,13)$. Thus, neonatal cortisone administration should not affect first and second molar crown size in rats (Table 1) because onset of calcification for these teeth is initiated prenatally, but it might delay the mineralization of these teeth and retard their eruption. Maintenance of normal crown size of the mandibular first and second molars after neonatal cortisone administration has been reported (11).

There is general accord that the administration of cortisone retards dentinogenesis, but that enamel widths are unaffected (1, $8,9)$. Ball (1) found that the increased incisal eruption rate noted in the cortisone-treated rat was associated with a significant in-
Table 3. Formative dental chronology in rats $(3,6)^{1}$

\begin{tabular}{lccc}
\hline & $\begin{array}{c}\text { Onset of calcifica- } \\
\text { tion }\end{array}$ & Crown completed & Eruption \\
\hline 1st molar & $\begin{array}{c}4 \text { days prenatal } \\
\text { 17 days insemina- } \\
\text { tion }\end{array}$ & 10 days postnatal & 19 days \\
2nd molar & $\begin{array}{c}2 \text { days prenatal } \\
\text { 19 days insemina- } \\
\text { tion }\end{array}$ & 15 days postnatal & 22 days \\
3rd molar & 10 days postnatal & 25 days postnatal & 35 days \\
\hline
\end{tabular}

' Dental formula: $I, M_{1}, M_{2}, M_{3}$. Incisor formation begins at 16 days insemination with eruption at 10 days postnatal.

crease in the size of the pulp chamber and a significant decrease in the thickness of the dentin walls.

Johannessen (9) reported site-specific reductions in dentin formation, but found no clearcut association between unevenly reduced dentinogenesis and somatic growth. Experimental interferences with the growth of tooth germs during critical developmental periods have been imposed by malnutrition and specific nutritional deprivation during pregnancy and lactation with low body weights at weaning $(5,8)$. However, Davidowitch (4) demonstrated that the suppression of somatic growth as a direct result of cortisone administration cannot be entirely accounted for by reduction of food intake.

The direct effect of neonatal cortisone administration on the morphodifferentiation of the third molar, which does not begin calcification until age 10 days (Table 3 ) is demonstrated by the permanent reduction of coronal dimension and the permanent anatomic coronal variations. Studies on the interference with craniofacial growth $(10,11)$ and the retardation of endosteal resorption after cortisone usage $(2,7)$ introduce the possibility that, in addition to a primary fault in odontogenic matrix formation, inhibition of normal resorptive modeling perifollicularly might additionally alter a developing tooth bud anatomically. The 


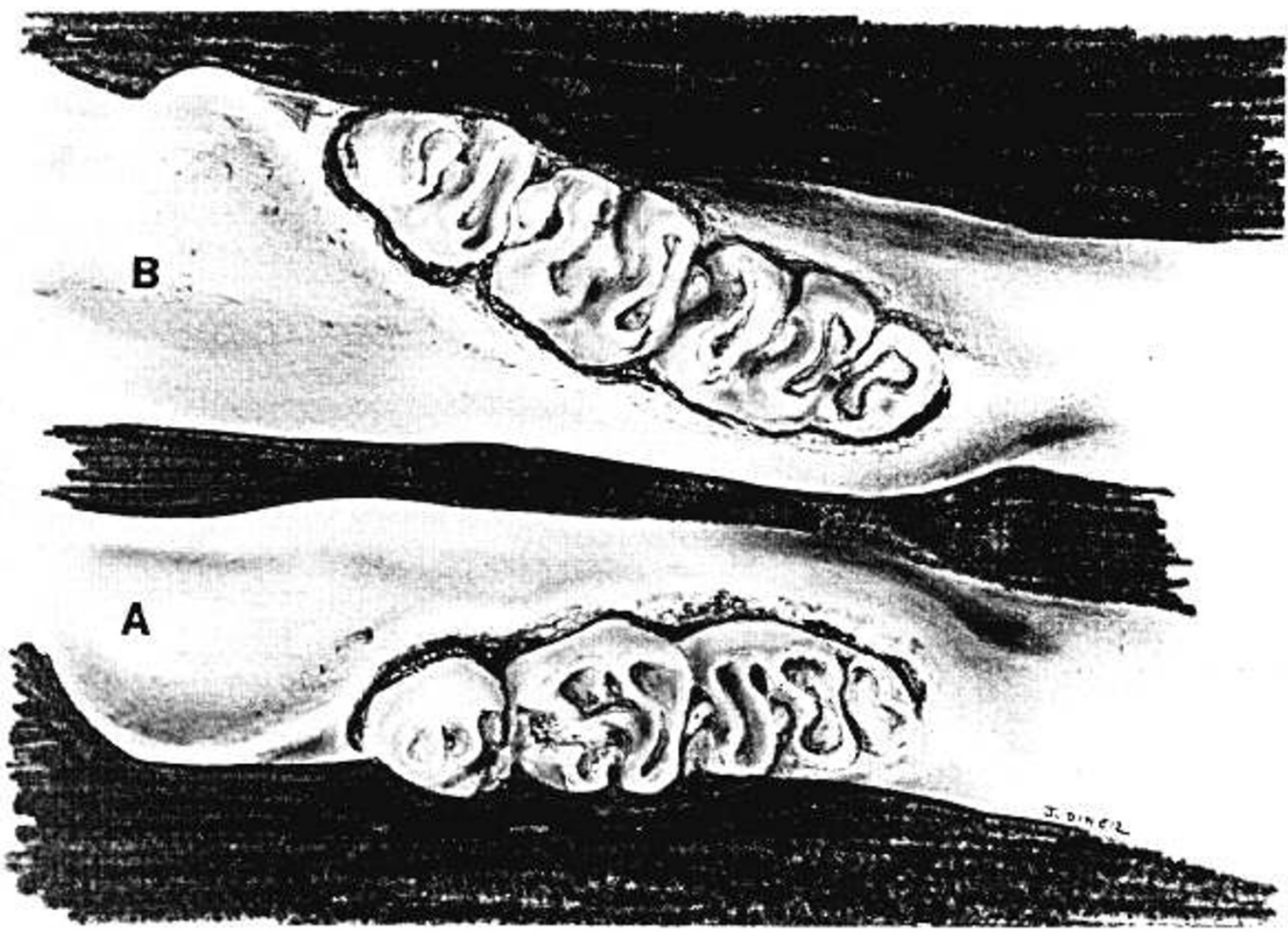

Fig. 4. Dried mandibles of treated $(A)$ and control $(B)$ animals at 84 days of age. Third molar crown and morphology in the treated animal are still abnormal.

growth of the tooth germ and the adaptation of the bony crypt to the increasing size of the tooth germ are closely related and interdependent $(14,15)$. This suggests that some of the developmental and maturational changes noted in this study may be secondarily imposed by the physical alteration of the surrounding tissues.

\section{CONCLUSION}

The effects of neonatal cortisone on the developing rat dentition are considerably less profound than the changes imposed on somatic growth. Only those developing teeth which had not reached the appositional stage were permanently affected. This might indicate that cortisone, at the appropriate time and dosage, exerts its greatest influence on the primary odontogenic matrix, and, secondarily, might exert a delaying force on dental maturation and the normal resorptive mechanisms of alveolar bone.

\section{REFERENCES AND NOTES}

1. Ball, P. C.: Dimensional changes in the dental tissues of the rat mandible incisor after the administration of glucocorticoid hormone. J. Dent. Res., 51: 1260 (1972).

2. Bernick, S., and Ershoff, B. H.: Histochemical study of bone in cortisone treated rats. Endocrinology, 72: 231 (1963).

3. Bhaskar, S. N.: Growth pattern of the rat mandible from 13 days insemination age to 30 days after birth. Amer. J. Anat., 92: 1 (1953).

4. Davidowitch, Z.: Radiographic and autoradiographic study on the effects of cortisone on bone growth in albino rats. Arch. Oral Biol., 16: 897 (1971).

5. DiOrio, L. P., Miller, S. A., and Navia, J. M.: The separate effects of protein and calorie malnutrition and the development and growth bones of rat bones and teeth. J. Nutr., 14: 856 (1973).

6. Farris, E. J., and Griffith, J. Q.: The Rat in Laboratory Investigation, Ed. 2 (J. Lippincott, Philadelphia, 1949).
7. Goldsmith, E. D., and Ross, L.: Effects of long-term cortisone treatment on the supporting dental structures of the rat [Abstr.]. Thirty-first General Meeting of the International Association of Dental Research. J. Dent. Res., 32: 699 (1953).

8. Holloway, P. J., Shaw, J. H., and Sweeney, E. A.: Effects of various sucrose:casein ratios in purified diets on the teeth and supporting structures of rats. Arch. Oral Biol., 3: 185 (1961).

9. Johannessen, L. B.: Effects of cortisone on dentinogenesis in mandibular first molars of albino rats. Arch. Oral Biol., 9: 421 (1964).

10. Massler, M., and Schour, I.: The growth pattern of the cranial vault in the albino rat as measured by vital staining with alizarin red "S." Anat. Rec., 110: 83 (1951).

11. Moss, M. L.: Morphological changes in the growing rat skull following administration of cortisone acetate. Proc. Soc. Exp. Biol., 89: 648 (1955).

12. Orban's Oral Histology and Embryology, Ed. 7. In: H. Sicher and S. N. Bhaskar: (C. V. Mosby Co., St Louis, 1972).

13. Pindborg, J. J.: Pathology of the Hard Dental Tissues, p. 185 (W. B. Saunders Co., Philadelphia, 1970).

14. Schour, I., Bhaskar, S. N., Greep, R. O., and Weinman, J. P.: Odontome like formation in a mutant strain of rats. Amer. J. Anat., 85: 73 (1949).

15. Shaw, J. H., and Griffiths, D.: Dental abnormalities in rats attributable to protein deficiency during reproduction. J. Nutr., 80: 123 (1963).

16. Sobel, E. H.: Effects of neonatal stunting on the development of rats: Early and late effects of neonatal cortisone on physical growth and skeletal maturation. Pediat. Res., 12: 000 (1978)

17. Sofaer, J. A.: Genetic variations and tooth development: Research in dentistry. Brit. Med. Bull., 31: 107 (1975).

18. The authors express sincere appreciation to Mr. Jack Diner, Chief Medical Illustrator, University of Arkansas Medical Center, for the preparation of illustrations in this paper.

19. This research was supported in part by USPHS Project HD 05668 from the NIH by Research Grant R-256-73 from the United Cerebral Palsy Research and Educational Foundation, and by Maternal and Child Health Training Grant MCT000241-12-0, DHEW.

20. Requests for reprints should be addressed to: Dr. Edna H. Sobel, Albert Einstein College of Medicine, Bronx, NY 10461 (USA)

21. Received for publication July 19, 1977.

22. Accepted for publication December 14, 1977. 